\title{
Effects of gravel mulch on aeolian transport: a field wind tunnel simulation
}

\author{
KeCun ZHANG ${ }^{*}$, WeiMin ZHANG, LiHai TAN, ZhiShan AN, Hao ZHANG \\ Key Laboratory of Desert and Desertification, Cold and Arid Regions Environmental and Engineering Research Institute, Chinese \\ Academy of Sciences, Lanzhou 730000, China
}

\begin{abstract}
The shape, size and coverage of gravels have significant impacts on aeolian sand transport. This study provided an understanding of aeolian transport over the gravel mulching surfaces at different wind velocities by means of a mobile wind tunnel simulation. The tested gravel coverage increased from $5 \%$ to $80 \%$, with a progressive increment of $5 \%$. The gravels used in the experiments have three sizes in diameter. Wind velocities were measured using 10 sand-proof pitot-static probes, and mean velocity fields were obtained and discussed. The results showed that mean velocity fields obtained over different gravel mulches were similar. The analysis of wind speed patterns revealed an inherent link between gravel mulches and mean airflow characteristics on the gravel surfaces. The optimal gravel coverage is considered to be the critical level above or below which aeolian transport characteristics differ strongly. According to the present study, the optimal gravel coverage was found to be around $30 \%$ or $40 \%$. Threshold velocity linearly increased with gravel coverage. Sand transport rate first increased with height above the wind tunnel floor $\left(\mathrm{H}_{\mathrm{f}}\right)$, reaching a peak at some midpoint, and then decreased.
\end{abstract}

Keywords: gravel mulch; wind speed profile; sand transport; drag velocity

Citation: KeCun ZHANG, WeiMin ZHANG, LiHai TAN, ZhiShan AN, Hao ZHANG. 2015. Effects of gravel mulch on aeolian transport: a field wind tunnel simulation. Journal of Arid Land, 7(3): 296-303. doi: 10.1007/s40333-015-0121-1

Gobi is a prevalent type of aeolian geomorphology in arid and semi-arid regions. Its area is about $5.695 \times 10^{5} \mathrm{~km}^{2}$ in China. Gobi in western China is a potential dust source and represents an important source of aerosols that can be transported into East Asia and the North Pacific Ocean (Zhang et al., 1993; Wang et al., 2012).

Aeolian transport over Gobi has well been studied and documented in literature over the last several decades (Yin, 1989; Mckenna Neuman, 1998; Dong et al., 2004a; Zheng et al., 2004; Qu et al., 2005; Tan et al., 2013). This includes a change in flux profile of wind-blown sand caused by the obstacles of gravels (Yin, 1989; Zheng et al., 2004; Qu et al., 2005) and the establishment of aeolian transport equations over Gobi (Dong et al., 2004a; Tan et al., 2013). Wind tunnel results of Mckenna Neuman (1998) revealed that the spacing between gravels was an important factor influencing aeolian transport over stable deflation lag surfaces. However, studies on the impact of shape, size and coverage of gravels on aeolian transport were still limited.

The transport and deposition of aeolian sands are intimately associated with the regional wind regime and characteristics of underlying surfaces. In turn, wind regime has a potentially large radiative impact on aeolian geomorphology. Gravel mulch is a prominent layer of pebbles embedded in and/or scattered on the earth surface and is a characteristic feature of deserts (Schmiedle and Jurgens, 2004). It increases the aero-dynamic roughness of gravel beds and protects the underlying soil from erosion (Kaseke et al., 2012).

There is a large area of Gobi in Northwest China, which are mainly distributed around deserts with sparse vegetation, barren soil and scarce surface water

*Corresponding author: KeCun ZHANG (E-mail: kecunzh@lzb.ac.cn)

Received 2014-06-25; revised 2014-09-25; accepted 2014-10-10

(C) Xinjiang Institute of Ecology and Geography, Chinese Academy of Sciences, Science Press and Springer-Verlag Berlin Heidelberg 2015 
(Wu, 1987). Wind-blown sand occurs frequently and damages agricultural infrastructures. Therefore, how to control the sand damage effectively and scientifically in Gobi regions has become a new challenge in China.

The aims of this study include: 1) to illustrate the characteristics of aeolian sand flux over Gobi surface, such as wind-blown sand flux and wind speed profile; and 2) to show the impacts of gravel mulch on aero-dynamic roughness, drag velocity, sand transport and shear stress that forces on the initiation of sand grains. The results are important for future studies on aeolian geomorphology and for attempts to control the damage caused by wind-blown sand in Gobi regions.

\section{Materials and methods}

The experiments were performed on the undisturbed Gobi surfaces atop the Mogao Grottoes, Dunhuang, China. The Mogao Grottoes is a well-known cultural site under special protection by the Chinese government and the World Heritage Committee. The Mogao Grottoes have been suffering from serious wind-blown sand problems for centuries because it is bordered by the Sanwei Mountain to the east and the Mingsha Mountain to the west (Qu et al., 2001; Stone, 2008). The Gobi surface atop the Mogao Grottoes stretches 700 to $1,000 \mathrm{~m}$ westward to the Mingsha Megadune. The land surface changes from gravel Gobi near the cliff to sandy Gobi near the western sand dunes. The megadunes provide abundant sand materials for the westerly wind-blown sand. The winds in the Mogao Grottoes are multidirectional and strongly seasonal. The wind regime is reflected in the wind rose and potential sand-drift vector, which shows a net resultant transport vector of 78.1 units in a drift direction of $329^{\circ}$ (Liu et al., 2011). Three prevailing winds are: $\mathrm{S}$ wind, mainly caused by local air-circulation and is dominant in winter with high frequency (approximately 58\% of total wind events); NW wind, predominant in spring and summer with less frequency (about 24\%); and NE wind, also prevalent in spring and summer with the lowest frequency (about 18\%). The NW and S winds transport sand materials from the west to the Grottoes, whereas the NE wind blows the deposited sand on the Gobi sur- face back to the Megadunes. The greatest potential threat is the migration of sand from the eastern edge of the Mingsha Mountain to the western side of the cliff top of the Grottoes.

To simulate the effects of gravel mulch on the process of aeolian transport, we conducted simulation experiments using a mobile wind tunnel from the Key Laboratory of Desert and Desertification, Chinese Academy of Sciences (Fig. 1). This blow-type noncirculating wind tunnel has a total length of $11.4 \mathrm{~m}$ and is composed of an entrance section ( $0.6 \mathrm{~m}$ long), a power section ( $1.2 \mathrm{~m}$ long), an expansion section (0.8 $\mathrm{m}$ long), a stabilization section ( $0.5 \mathrm{~m}$ long), a compression section (1.3 m long), a working section (6.0 $\mathrm{m}$ long) and a diffusion section (1.0 m long). The working section has a cross-sectional area of 60 $\mathrm{cm} \times 60 \mathrm{~cm}$. Wind speed can be changed continuously from 0 to $20 \mathrm{~m} / \mathrm{s}$, and the thickness of the boundary layer in the working section can reach $23 \mathrm{~cm}$.

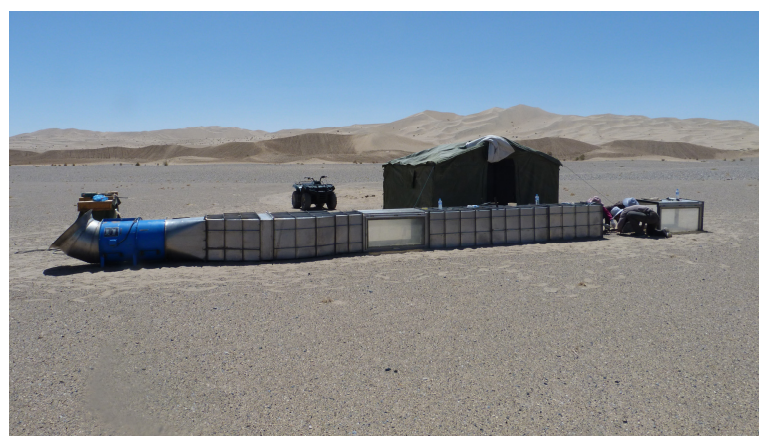

Fig. 1 Photograph of mobile wind tunnel experiments

The gravels used in the experiments, with average respective length, width and height of $3 \mathrm{~cm} \times 2 \mathrm{~cm} \times 2 \mathrm{~cm}$, were chosen from the gravel beds which are widely distributed atop the Mogao Grottoes. The coverage of each kind of gravel mulch refers to the ratio of the total gravel base area to the area of the working surface. The coverage of gravel mulch was calculated by the area of contour projected onto a grid paper, and it ranged from $5 \%$ to $80 \%$, with a progressive increment of $5 \%$. The area of the working surface was constant, and thus gravel coverage was controlled by evenly paving the gravels on a graph paper to $30 \%$ of the working surface area, whereafter these gravels were evenly paved to the entire working surface. All the tested gravels in the ex- 
periments were arranged in rhombus patterns (Tan et al., 2013). For understanding the effect of gravel obstacles on aeolian transport, simulation experiments without gravel mulch in wind tunnel were also conducted as a control test. Experimental wind velocities were $6,8,10,12$ and $14 \mathrm{~m} / \mathrm{s}$, respectively, as measured by using a pitot-static probe placed in the centre of the wind tunnel at a height of $30 \mathrm{~cm}$ above the ground. Wind velocity was measured by using an X-type sand-proof pitot-static probe with a measurement error of less than $0.15 \%$ (Dong et al., 2002). The wind profiler was placed $0.6 \mathrm{~m}$ after the downwind edge of the gravel bed to measure the centerline wind velocity. The vertical distribution of blowing sand was measured by using a sand trap with a height of $20 \mathrm{~cm}$ and a width of $2 \mathrm{~cm}$. Two sand traps were used in the simulation experiments and laid $2.5 \mathrm{~m}$ and $5.0 \mathrm{~m}$, respectively, downwind from the entrance of the working section in the wind tunnel. The gravels were spread evenly at the space of the two sand traps. Sand used in the wind tunnel experiments was from the Mingsha Mountain near the experimental site. The average grain size composition of sand used in the experiments was listed in Table 1.

Table 1 Grain size composition of sand grains used in the experiments

\begin{tabular}{lcccc}
\hline & $\begin{array}{c}\text { Coarse } \\
\text { sand }\end{array}$ & $\begin{array}{c}\text { Medium } \\
\text { sand }\end{array}$ & Fine sand & $\begin{array}{c}\text { Very fine } \\
\text { sand }\end{array}$ \\
\hline Grain size range (mm) & $1.6-0.5$ & $0.50-0.25$ & $0.25-0.125$ & $0.125-0.063$ \\
Percent content (\%) & 0.02 & 40.21 & 51.05 & 8.71 \\
\hline
\end{tabular}

\section{Results and discussion}

\subsection{Wind velocity in the wind tunnel without ob- stacles}

Fluid flows can be described as being laminar or turbulent. Laminar flow is rare in air even without any obstacles (Livingstone and Warren, 1996). The role of turbulence is to vary lift and shear forces on the bed, and then entrain sand grains (Chepil and Siddoway, 1959). In a neutral, stable atmospheric boundary layer, wind velocity usually increases logarithmically with height above the underlining surface (z) (Bagnold, 1941). The results from the wind velocity profiles in the wind tunnel without barriers reveal that the wind velocity follows a logarithmic scale as a function of height above the wind tunnel floor $\left(\mathrm{H}_{\mathrm{f}}\right)$ (Fig. 2).

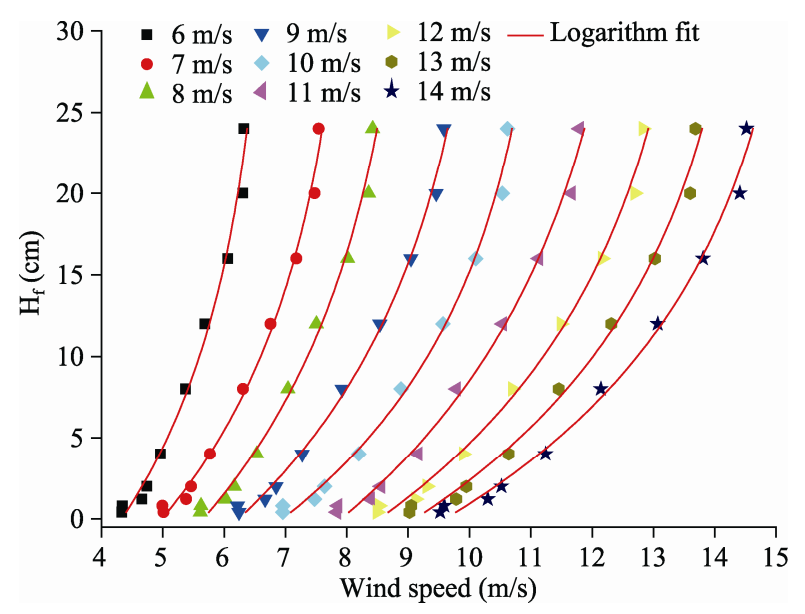

Fig. 2 Wind speed profiles of the bed without obstacles under different experiential wind speeds. $\mathrm{H}_{\mathrm{f}}$ at the vertical axis refers to the height above the wind tunnel floor (the same below).

The profiles can be described by the widely applied models using the law of the wall $(\mathrm{Wu}, 1987)$ as follows:

$$
u_{z}=\left(u_{*} / \mathrm{K}\right) \ln \left(z / z_{0}\right) .
$$

Where, $u_{z}$ is wind speed at height $z ; u_{*}$ is drag velocity; $\mathrm{K}$ is Karman's constant, usually taken as $0.4 ; z_{0}$ is roughness length dependent on the surface texture.

Regressions by the least square method indicate that the change of mean wind velocity with $z$ can be expressed by a logarithmic function as follows (Dong et al., 2001).

$$
\bar{u}=a+b \ln z .
$$

Where, $\bar{u}$ is time-averaged wind velocity at different $\mathrm{z}$ values; $a$ and $b$ are coefficients.

\subsection{Aerodynamic characteristics of Gobi bed with different gravel coverages}

\subsubsection{Wind speed profile}

The wind speed profiles over Gobi bed with different coverages of gravel mulch were shown in Fig. 3. The wind speed profiles were well fitted with $\mathrm{H}_{\mathrm{f}}$ and comply with the law of the wall. The pattern of wind speed profiles was also determined by the features of the underlying surface. At the same $\mathrm{H}_{\mathrm{f}}$ within the boundary layer, the wind speed increased with the gravel coverage on Gobi surface. 

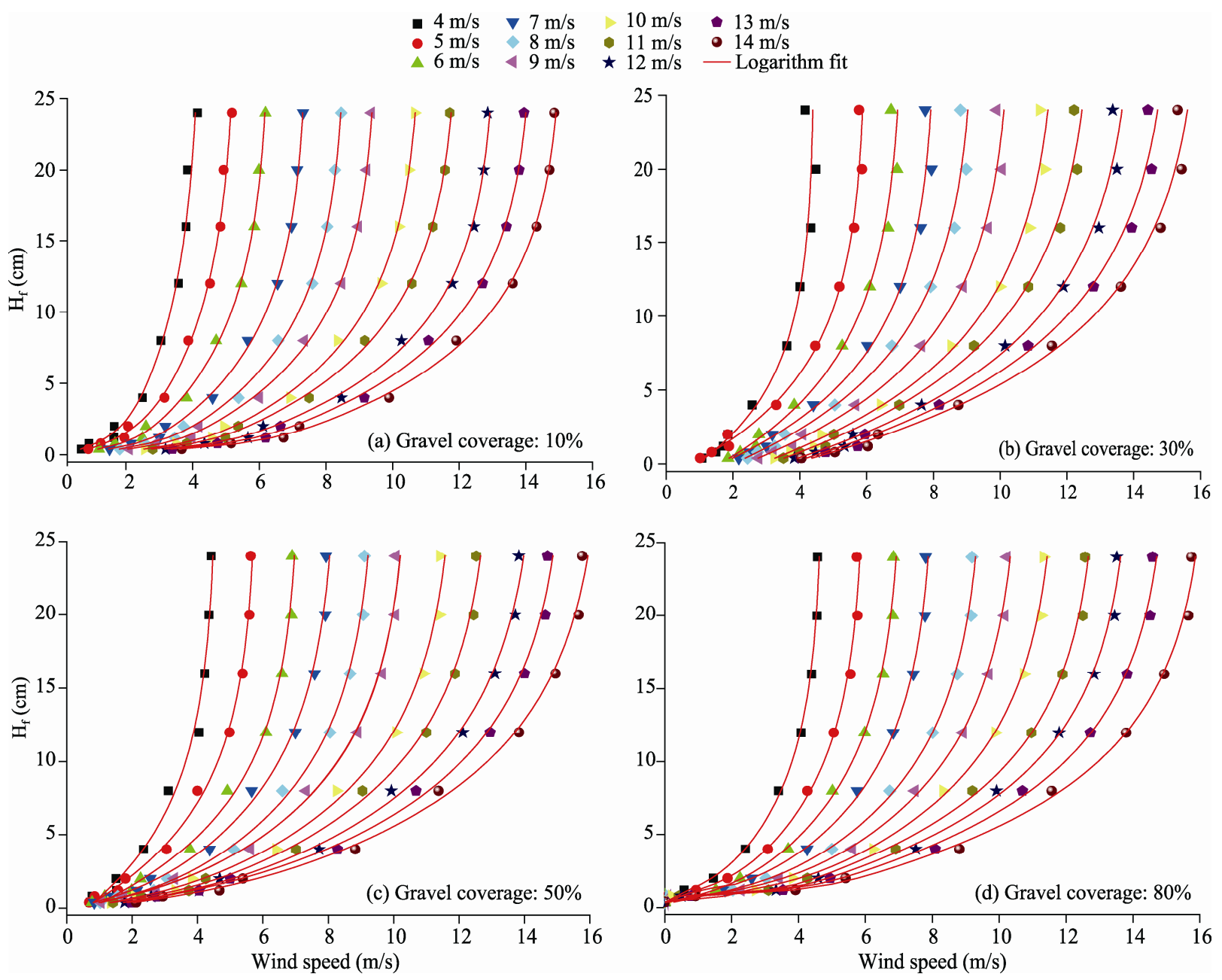

Fig. 3 Wind speed profiles of Gobi beds with different gravel coverages under different experimental wind speeds

2.2.2 Effect of gravel coverage on the threshold of sand movement

Threshold velocity is very critical for sand movement. Once the wind speed exceeds threshold velocity, sand grains are entrained, and they move in several distinct ways with increasing wind velocity, that is, creep, saltation and suspension (Livingstone and Warren, 1996). Threshold velocity is determined by many factors, such as the size of particle, humidity of soil and material composition (Wiggs et al., 2004; Stout, 2007; Stout and Arimoto, 2010). Besides these factors, the characteristic of underlying surface is also a determinant factor of threshold velocity. The relationship between threshold velocity and gravel coverage on Gobi surface was shown in Fig. 4. The threshold velocity was significantly correlated with gravel coverage $\left(R^{2}=0.97\right)$. Threshold velocity increased linearly

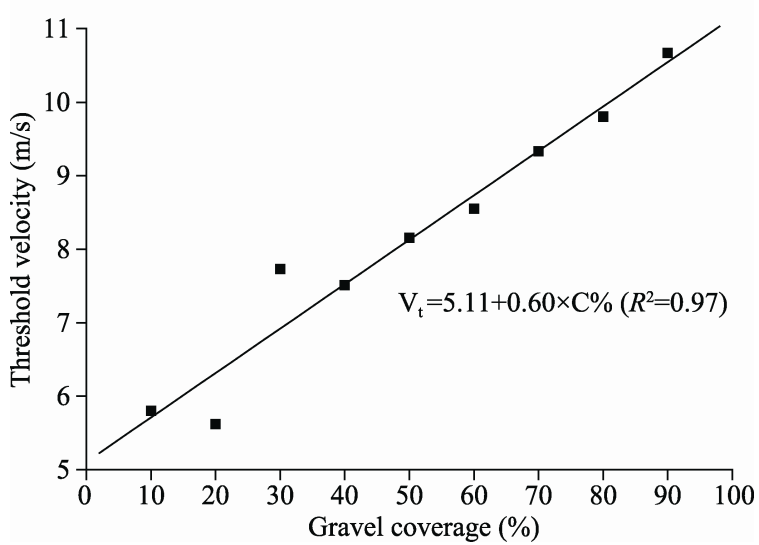

Fig. 4 The relationship between threshold velocity and gravel coverage

with gravel coverage. When gravel coverage was $10 \%$, the threshold velocity for sand was $5.8 \mathrm{~m} / \mathrm{s}$ at a $\mathrm{H}_{\mathrm{f}}$ of 
$30 \mathrm{~cm}$ in the wind tunnel. When gravel coverage increased to $90 \%$, the threshold velocity increased to $10.7 \mathrm{~m} / \mathrm{s}$ accordingly.

2.2.3 Aero-dynamic roughness

When wind blows over an immobile surface, there is a shallow layer above the surface where the velocity is zero. The thickness of this layer is known as the aero-dynamic roughness (Cook et al., 1993). Table 2 listed the values of aeo-dynamic roughness above the Gobi surface with different coverages of gravel mulch. Aeo-dynamic roughness increased linearly with gravel coverage, from $0.06 \mathrm{~cm}$ at the coverage of $5 \%$ to 0.53 $\mathrm{cm}$ at $80 \%$.

Table 2 The relationship between aero-dynamic roughness and gravel coverage

\begin{tabular}{cc}
\hline Gravel coverage $(\%)$ & Aero-dynamic roughness $(\mathrm{cm})$ \\
\hline 5 & 0.06 \\
10 & 0.10 \\
15 & 0.16 \\
20 & 0.22 \\
25 & 0.17 \\
30 & 0.16 \\
35 & 0.30 \\
40 & 0.30 \\
45 & 0.27 \\
50 & 0.34 \\
55 & 0.30 \\
60 & 0.41 \\
65 & 0.33 \\
70 & 0.63 \\
75 & 0.59 \\
80 & 0.53 \\
\hline
\end{tabular}

\subsubsection{Drag velocity and shear stress}

The energy available for entraining sand particles comes from wind. The stronger wind speed near the bed is, the higher shear force is produced. The drag velocity is related to the shear stress exerted by the wind on the bed and to the density of air (Pye, 1987). As the wind speed increased, the drag velocity increased linearly on Gobi surfaces irrespective of gravel coverage (Fig. 5).

Generally, the values of drag velocity and shear stress increased linearly with coverage of gravel mulch (Table 3). Under the gravel coverage of 5\%, the drag

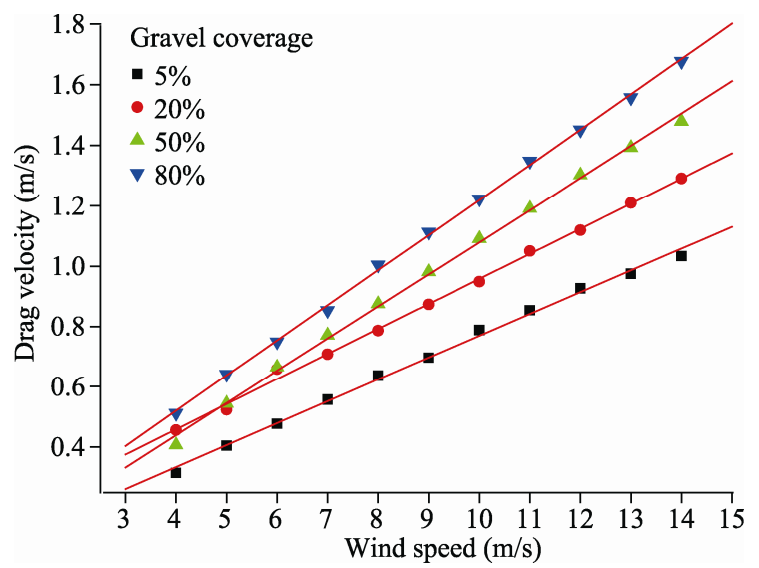

Fig. 5 The relationship between drag velocity and wind speed under different gravel coverages

Table 3 The values of drag velocity and shear stress changing with gravel coverage

\begin{tabular}{ccc}
\hline Gravel coverage (\%) & Drag velocity $(\mathrm{m} / \mathrm{s})$ & Shear stress $\left(\mathrm{N} / \mathrm{m}^{2}\right)$ \\
\hline 5 & 0.62 & 0.70 \\
10 & 0.75 & 0.76 \\
15 & 0.87 & 0.82 \\
20 & 0.99 & 0.88 \\
25 & 0.83 & 0.80 \\
30 & 0.84 & 0.81 \\
35 & 1.11 & 0.93 \\
40 & 1.16 & 0.95 \\
45 & 1.10 & 0.92 \\
50 & 1.22 & 0.97 \\
55 & 1.13 & 0.94 \\
60 & 1.31 & 1.01 \\
65 & 1.17 & 0.95 \\
70 & 1.63 & 1.12 \\
75 & 1.62 & 1.12 \\
80 & 1.57 & 1.10 \\
\hline
\end{tabular}

velocity and shear stress was $0.62 \mathrm{~m} / \mathrm{s}$ and $0.70 \mathrm{~N} / \mathrm{m}^{2}$, respectively. When gravel coverage reached $40 \%$, the drag velocity and shear stress correspondingly increased to $1.16 \mathrm{~m} / \mathrm{s}$ and $0.95 \mathrm{~N} / \mathrm{m}^{2}$, respectively.

\subsection{The effects of gravel mulch on sand transport}

The effect of gravel mulch is to restrict the movement of sand, either by trapping sand already being transported or by preventing or restricting entrainment on the bed. Many studies on aeolian sediments have been reported in literature (McEwan et al., 1992; Nalpanis et al., 1993; Remigius, 2003). At a given wind veloc- 
ity, the conditions of the underlying surface can influence sediment flux, which is because different surfaces have different effects on threshold velocity, migration of transported particles and deposition processes. On Gobi surface, due to the collision of sand grains with gravels interspersed on the bed, the structure of sand flux presents a peculiar characteristic (Zhang et al., 2008). The peak sand flux appeared at a certain $\mathrm{H}_{\mathrm{f}}$ above Gobi surface, which differs from that on sand dunes (Fig. 6). Above this peak, the sand flux decreased with $\mathrm{H}_{\mathrm{f}}$; while below this peak, the sand flux increased with $\mathrm{H}_{\mathrm{f}}$. On mobile dunes, the sand transport decreased exponentially with $\mathrm{H}_{\mathrm{f}}$ (Dong et al., 2004b).

Sand transport rate is defined as the mass of sediments passing through a plane perpendicular to the

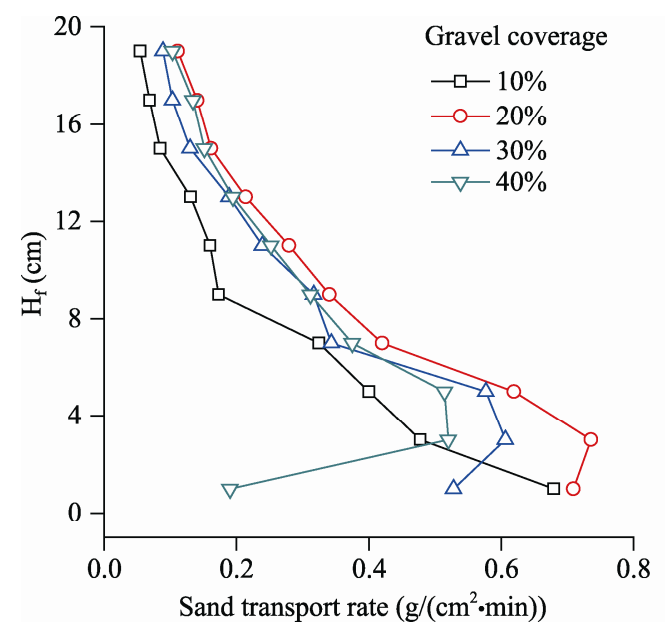

wind direction per unit time. Sand transport is closely related to sand supply and wind speed. On the condition of ample sand available, the sand transport rate increases with the cube of wind speed over the surface of sand dune (Bagnold, 1941). While on Gobi surface, due to the insufficient sand supply and the trap of gravels interspersed on the bed, sand transport rate was strongly correlated with the same power of wind velocity $\left(R^{2}>0.95\right.$; Fig. 7$)$.

When sand particles pass over the Gobi surface, some of them will be trapped by the gravels. In order to reflect the capability of Gobi surfaces for trapping sand particles traversing them, sand-intercepting efficiency was introduced. There was an increase in the sand-intercepting efficiency on Gobi bed with gravel coverage (Fig. 8). Generally, the sand-intercepting

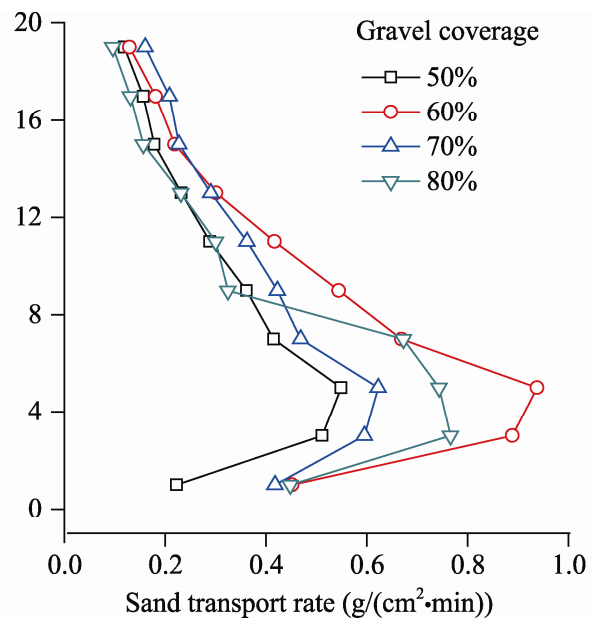

Fig. 6 Structure of sand flux on Gobi bed under different gravel coverages
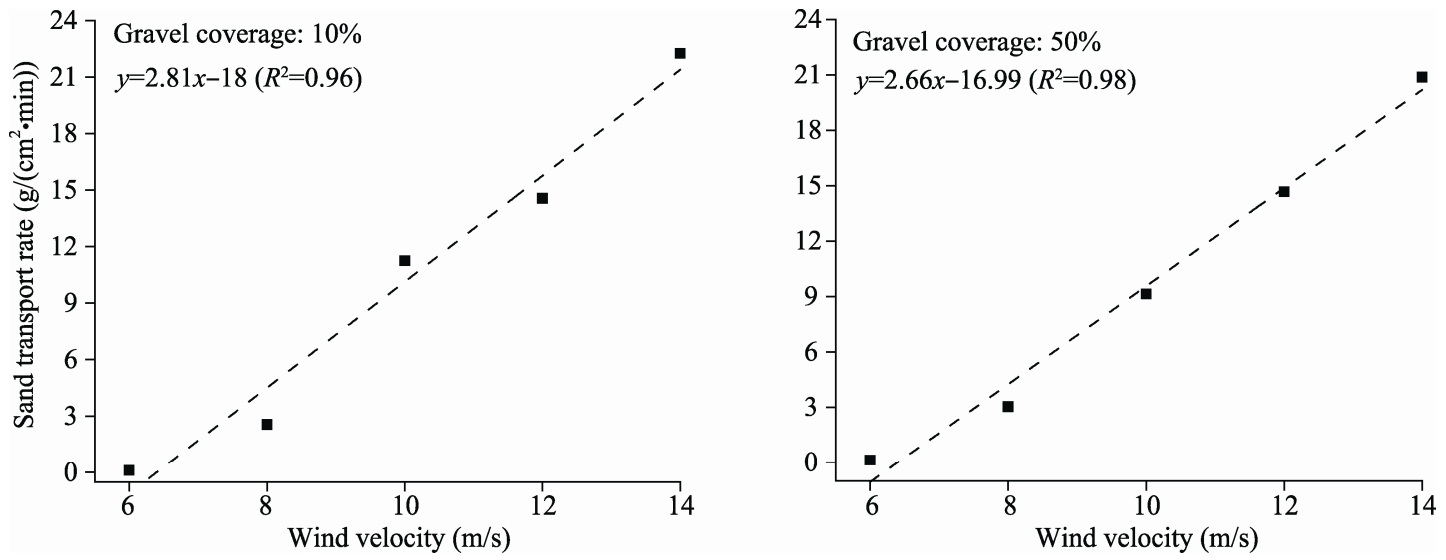

Fig. 7 The relationship between sand transport rate and wind speed 
efficiency exceeds $40 \%$ on Gobi surfaces, especially for the gravel coverage of $40 \%$ which has an efficiency of $62 \%$ (more than a half of sand particles are trapped by the gravels).

The change of cumulative content of sand grains in different $\mathrm{H}_{\mathrm{f}}$ with gravel coverage was shown in Fig. 9. Commonly, the cumulative content of sand flux in the same $\mathrm{H}_{\mathrm{f}}$ increased with gravel coverage. This phenomenon was mainly caused by the fact that the carried energy of creeping sand grains on Gobi surface increases with gravel coverage. When creeping sand grains collide with gravels on Gobi surface, they will bounce and take the motion of saltation with a big angle.

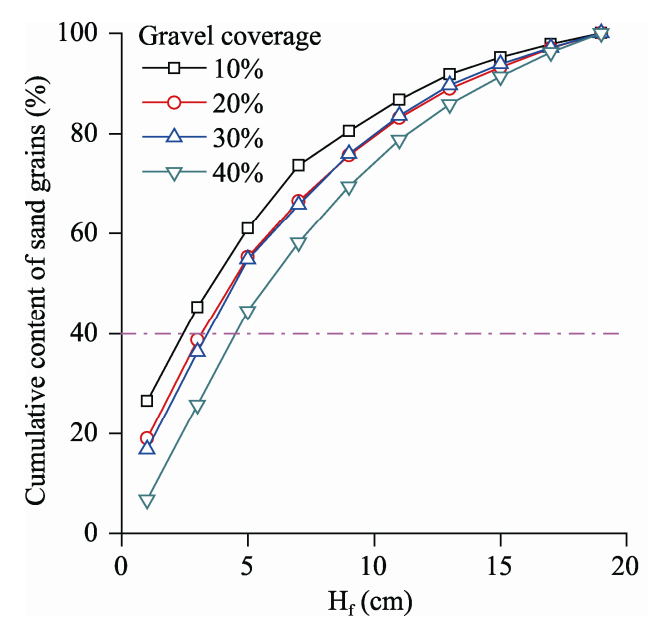

Fig. 9 Cumulative content of sand grains in different heights under different gravel coverages

\section{Conclusions}

Our study results suggest that the wind profiles on Gobi surface comply with the law of the wall and can be well fitted with height $\mathrm{H}_{\mathrm{f}}$. The threshold velocity was strongly correlated with gravel coverage. The values of drag velocity and shear stress increased linearly with gravel coverage. Due to the insufficient sand supply and the trap of gravels interspersed on the bed, sand transport rate was significantly correlated with wind velocity. When the gravel coverage increased to $40 \%$, the sand-intercepting efficiency was $62 \%$, which means more than a half of sand particles were trapped by the gravels.

Although many sand-control measures have been adopted, sand damage on the Mogao Grottoes still

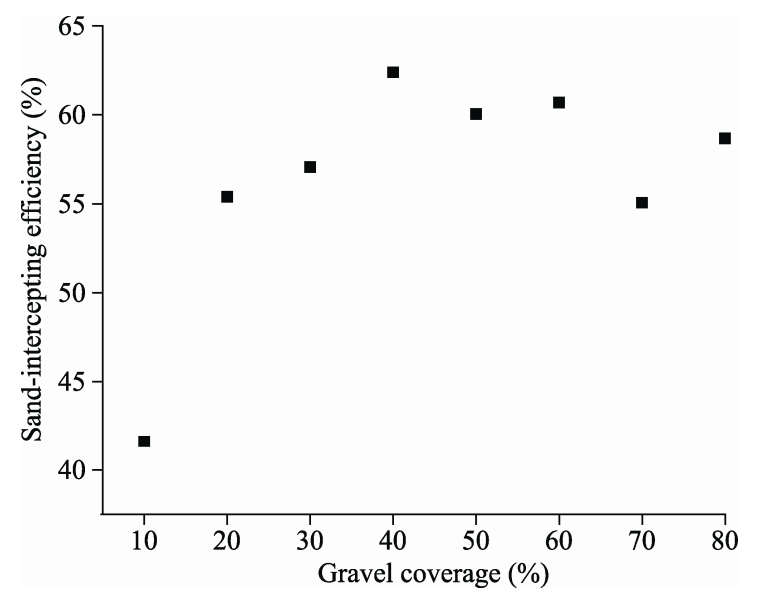

Fig. 8 The relationship between sand-intercepting efficiency and gravel coverage

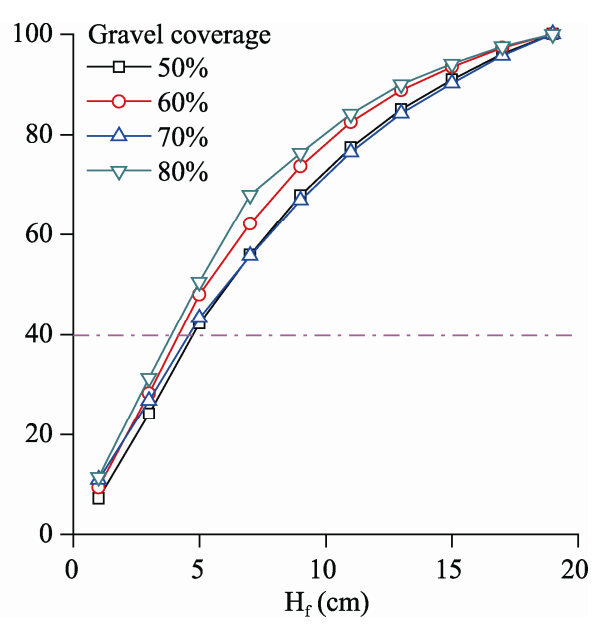

remains as a problem. Our results have several implications for the design of future sand-control management in the Mogao Grottoes and other Gobi regions. First, the results confirm the strong influence of gravel mulch on threshold velocity. The increase of gravel coverage can decrease wind velocity sufficiently. Second, sand transport rate increased linearly with wind speed on Gobi surface. Third, the results can be used to guide the design and testing of sand-control structures in our study area. A similar approach can also be used in other Gobi regions of the world that experience threats from wind-blown sand.

\section{Acknowledgments}

This research was supported by the Key Program of Knowledge Innovation Project of the Chinese Academy of Sciences 
(KZCX2-EW-313), the National Basic Research Program of China (2012CB026105) and the National Natural Science Foundation of China (41371027).

\section{References}

Bagnold R A. 1941. The Physics of Blown Sand and Desert Dunes. London: Methuen.

Chepil W S, Siddoway F H. 1959. Strain-gauge anemometer for analyzing various characteristics of wind turbulence. Journal of Meteorology, 16: 411-418.

Cook R, Warren A, Goudie A. 1993. Desert Geomorpholgoy. London: UCL Press Ltd.

Dong Z B, Gao S Y, Fryrear D W. 2001. Drag coefficients, roughness length and zero-plane displacement height as disturbed by artificial standing vegetation. Journal of Arid Environments, 49: 485-505.

Dong Z B, Liu X P, Wang X M. 2002. Aerodynamic roughness of gravel surfaces. Geomorphology, 43: 17-31.

Dong Z B, Wang H T, Liu X P, et al. 2004a. A wind tunnel investigation of the influences of fetch length on the flux profile of a sand cloud blowing over a gravel surface. Earth Surface Processes and Landforms, 29(13): 1613-1626.

Dong Z B, Wang H T, Liu X P, et al. 2004b. The blown sand flux over a sandy surface: a wind tunnel investigation on the fetch effect. Geomorphology, 57: 117-127.

Kaseke K F, Mills A J, Henschel J, et al. 2012. The effects of desert pavements (gravel mulch) on soil micro-hydrology. Pure and Applied Geophysics, 169: 873-880.

Liu B L, Zhang W M, Qu J J, et al. 2011. Controlling windblown sand problems by an artificial gravel surface: a case study over the gobi surface of the Mogao Grottoes. Geomorphology, 134: 461-469.

Livingstone L, Warren A. 1996. Aeolian geomorphology: an introduction. Singapore: Longman Singapore Publisher Ltd.

McEwan I K, Willetts B B, Rice M A. 1992. The grain/bed collision in sand transport by wind. Sedimentology, 39: 971-981.

Mckenna Neuman C. 1998. Particle transport and adjustments of the boundary layer over rough surfaces with an unrestricted, upwind supply of sediment. Geomorphology, 25: 1-17.

Nalpanis P, Hunt J C R, Barrett C F. 1993. Saltating particles over flat beds. Journal of Fluid Mechanics, 251: 661-685.

Pye K. 1987. Aeolian Dust and Dust Deposits. London: Academic Press.
Qu J J, Huang N, Dong G R, et al. 2001. The role and significance of the Gobi Desert pavement in controlling sand movement on the cliff top near the Dunhuang Magao Grottoes. Journal of Arid Environments, 48: 357-371.

Qu J J, Huang N, Tuo W Q. 2005. Structural characteristics of Gobi sand-drift and its significance. Advances in Earth Science, 20(1): 19-23. (in Chinese)

Remigius E O. 2003. Wind tunnel study on aeolian saltation dynamics and mass flow. Journal of Arid Environments, 53: 569-583.

Schmiedle U, Jurgens N. 2004. Habitat ecology of southern African quartz fields: studies on the thermal properties near the ground. Plant Ecology, 170: 153-166.

Stone R. 2008. Shielding a Buddhist shrine from the howling desert sands. Science, 321: 1035.

Stout J E. 2007. Simultaneous observations of the critical aeolian threshold of two surfaces. Geomorphology, 85: 3-16.

Stout J E, Arimoto R. 2010. Threshold wind velocities for sand movement in the Mescalero Sands of southeastern New Mexico. Journal of Arid Environments, 74: 1456-1460.

Tan L H, Zhang W M, Qu J J, et al. 2013. Aeolian sand transport over gobi with different gravel coverages under limited sand supply: a mobile wind tunnel investigation. Aeolian Research, 11: 67-74.

Wang X M, Hua T, Zhang C X, et al. 2012. Aeolian salts in Gobi deserts of the western region of Inner Mongolia: gone with the dust aerosols. Atmospheric Research, 118: 1-9.

Wiggs G F S, Baird A J, Atherton R J. 2004. The dynamic effects of moisture on the entrainment and transport of sand by wind. Geomorphology, 59: 13-30.

Wu Z. 1987. Aeolian Geomorphology. Beijing: Science Press. (in Chinese)

Yin Y S. 1989. Study on sand drift in strong wind region in gravel desert. Journal of Desert Research, 9(4): 27-36. (in Chinese)

Zhang K C, Qu J J, Zu R P, et al. 2008. Characteristics of wind blown sand on Gobi and mobile sand surface. Environmental Geology, 54: 411-416.

Zhang X Y, Arimoto R, An Z S, et al. 1993. Atmospheric trace elements over source regions for Chinese dust: concentrations, sources and atmospheric deposition on the Loess Plateau. Atmospheric Environment, 27: 2051-2067.

Zheng X J, He L H, Wu J J. 2004. Vertical profiles of mass flux for windblown sand movement at steady state. Journal of Geophysical Research: Solid Earth, 109, B01106, doi:10.1029/2003JB002656. 